\title{
Ergonomics and design for all
}

\author{
Isabella Tiziana Steffan ${ }^{\mathrm{a}}$, Francesca Tosi ${ }^{\mathrm{b}}$ \\ a Studio Steffan-Progettazione \& Ricerca, Via G.C. Procaccini 69, 20154 Milan, Italy, info@studiosteffan.it \\ ${ }^{\mathrm{b}}$ University of Florence, Faculty of Architecture, Via San Niccolò 85, 50125 Florence, Italy, \\ francesca.tosi@taed.unifi.it
}

\begin{abstract}
The paper deals with research areas and actions thanks to which the theoretical and methodological content of the "Ergonomics in Design" project can give a concrete contribution to the "Design for All" project, in particular with regards to the assessment and design of environments, the design of everyday products.
\end{abstract}

Keywords: Everyday product s Design, Urban Design, User needs

\section{Introduction}

Much of what has recently been developed in the Ergonomics in Design area has numerous points of contact with the Design for All objectives and approach philosophy, as well as with the broader framework of theoretical and methodological tools produced over recent years in the Design for All research, aimed at defining the intervention criteria for weaker sections of the population.

The relationship and points of convergence between Ergonomics and Design for All have their origin in the focus placed by the ergonomic project on the specific nature and complexity of each case of intervention - irrespective of whether to assess or design a product, an environment or a service starting from the identification of specific requirements that users express or could express regarding their relationship with the product, depending on the equally specific conditions of the context within which said relationship is enacted, their reciprocal influence and variability over time.

In design terms, this approach allows - and requires - a shifting of attention from the identification of so-called user profiles, traditionally defined by age and/or specific physical or cognitive characteristics corresponding to specific needs, to a new design approach based on the identification of need profiles, understood as requirements, expectations, attitudes and desires related to the use of a particular product. In these need profiles in fact, it may be possible to identify user profiles that differ greatly one from the other.

Located within this conceptual and methodological step, from the design "for user profiles" and "levels of ability or inability" to the design for user needs and expectations", is the contribution that the project ergonomics could offer to the Design for All approach and, more generally, to design aimed at maximizing the possible number of potential users-individuals.

The ergonomics methodology can also represent a necessary and tangible contribution to the Design For All project. The cognitive tools as well as the evaluation methods of ergonomic product quality represent a concrete means of design and process innovation, capable of implementing numerous proposals and contents of the Design for All project in terms of operations and planning.

\section{Methodological approach: knowledge of the "use" context as a design reference}

Starting from the Design for All approach, of particular interest are the contents and intervention philosophy of the ICF "International Classification of Functioning, Disability and Health" and the international regulations provided by the ISO, pursuant to standard I20282/2006, "Ease of operation of everyday products - Part 1: Design requirements 
for context of use and user Characteristics - Part 2: Test method for walk-up-and-use products $20282 /$ "Ease of operation of everyday products" ; and also the ISO / IEC Guide 71 / 2001 "Guidelines for standard developers to address the needs of older persons and persons with disabilities".

Also of great interest is the mutual agreement between the User Centred Design's definition of the context of use, i.e. "users, goals, tasks, equipment (hardware, software and materials) and the physical environment and social context in which the product is used", and the definitions contained in the ICF "International Classification of Functioning, disability and Health", which describe the individual limitations deriving from diseases and/or disabilities and the limitations they may cause to individual and social activities.

The ICF classification describes the individual health conditions according to three different perspectives or dimensions: Body Functions and Structures ${ }^{1}$, Activity and Participation ${ }^{2}$, Contextual Factors $^{3}$. These three dimensions allow for defining functional levels and are designed from contextual factors, divided into environmental and personal factors.

So it is the contextual factors that determine the effective ability or disability conditions, based on the correlation between health and environment.

The contribution made by several regulatory instruments developed in the field of ergonomics and specifically aimed at the global user design is also of great interest. In particular, the ISO 20282/2006 standard, "Ease of operation of everyday products" that defines the ease-of-use on the basis of "percentage of users able to successfully reach/use the main features/services of a product using the

${ }^{1}$ Body Functions and Structures - describes actual anatomy and physiology/psychology of the human body.

${ }^{2}$ Activity and Participation - describes the person's functional status, including communication, mobility, interpersonal interactions, self-care, learning, applying knowledge, etc.

${ }^{3}$ Contextual Factors include:

Environmental Factors: factors that are not within the person's control, such as family, work, government agencies, laws, and cultural beliefs;

Personal Factors: race, gender, age, educational level, coping styles, etc. Personal factors are not specifically coded in the ICF because of the wide variability among cultures. They are included in the framework, however, because although they are independent of the health condition they may have an influence on how a person functions. product controls without additional assistance or training" and introduces a product classification related to the user-friendliness and level of competence (reading instructions, training, etc..) required for their use.

The standard's objective is to identify the category of "daily-use" products, deemed necessary for carrying out routine daily activities, and whose ease-of-use is the discriminating factor between the user's ability or inability to independently perform such activities.

Along the same lines is the Guide 71, aimed at providing information and basic knowledge on the needs of people with different ability levels.

In both cases the goal of the regulatory standards is to extend the usability meanings and fields of application, reinterpreting the User-Centred Design definitions in the everyday product field, and designing "for the maximum number of users. "

While "the ICF provides a framework that allows for measuring the role of the environment and the health outcomes on people, and at the same time more efficiently monitors the welfare and health interventions health in a transversal and interdisciplinary manner" 2 , the contribution offered by several regulatory standards is particularly interesting as they specifically target the project in human environments, aimed at facilitating orientation and mobility for visually impaired subjects, valid for all users.

The study "Report on Standardization of Fundamental Research Relating to tactile tiles for guiding the visually impaired" and subsequent updates by the Ministry of Trade and Industry of Japan in 1998, is the only experimental research published to date (from the National Institute for Technology and Evaluation) that deals with the orientation for visually impaired people in an urban environment.

Addressing the same issue, the standard CEN TS 15209 and ISO N 84, established the characteristics for creating horizontal tactile signs in relief, in order to provide perceivable information for the visually impaired via tactile sensations, the use of a cane, and high colour contrasts with the surrounding pavement surfaces.

Some nations, such as Spain, have already implemented this standard. In Italy, the UNI is preparing a standard called "Tactile pathways for people with visual sensory impairment. General design criteria".

From a methodological point of view, three reference points can be pinpointed for the 
development of an integrated approach to the Ergonomics - Design for All project.

The first point of interest focuses on the ergonomics and User-Centred Design approach towards specific needs which users express or could express with respect to their relationship with the product, depending on the equally specific conditions of the context in which said relationship is implemented, their reciprocal influence and variability over time.

This approach allows for shifting the attention from the user profiles traditionally defined by age, specific physical or cognitive characteristics, or specific limitations and relative design specialisations - design for the elderly, design for the disabled people, design for the visually impaired - to need profiles to which people with very different needs can identify.

The second point of interest is the mutual agreement between the UCD's definition of the context of use "the users and the objectives, tasks, equipment (hardware, software and materials) and the physical and social environment in which the product is used", and the definitions set down in the ICF "International Classification of Functioning, Disability and Health (international classification of functionality, disability and health) which describe the individual limitations or handicaps depending on the diseases and/or disabilities they may derive from and the opportunities or restrictions present in the the environment (physical, perceptual, social, economic, etc.).

Finally, the third point concerns the contribution that the methodological setup of the ergonomics can offer the Design for All project. The cognitive tools as well as the methods of assessing the ergonomic quality of the products could in fact represent practical design and process innovation instruments, capable of implementing numerous proposals and contents of the Design for All project in terms of operations and planning.

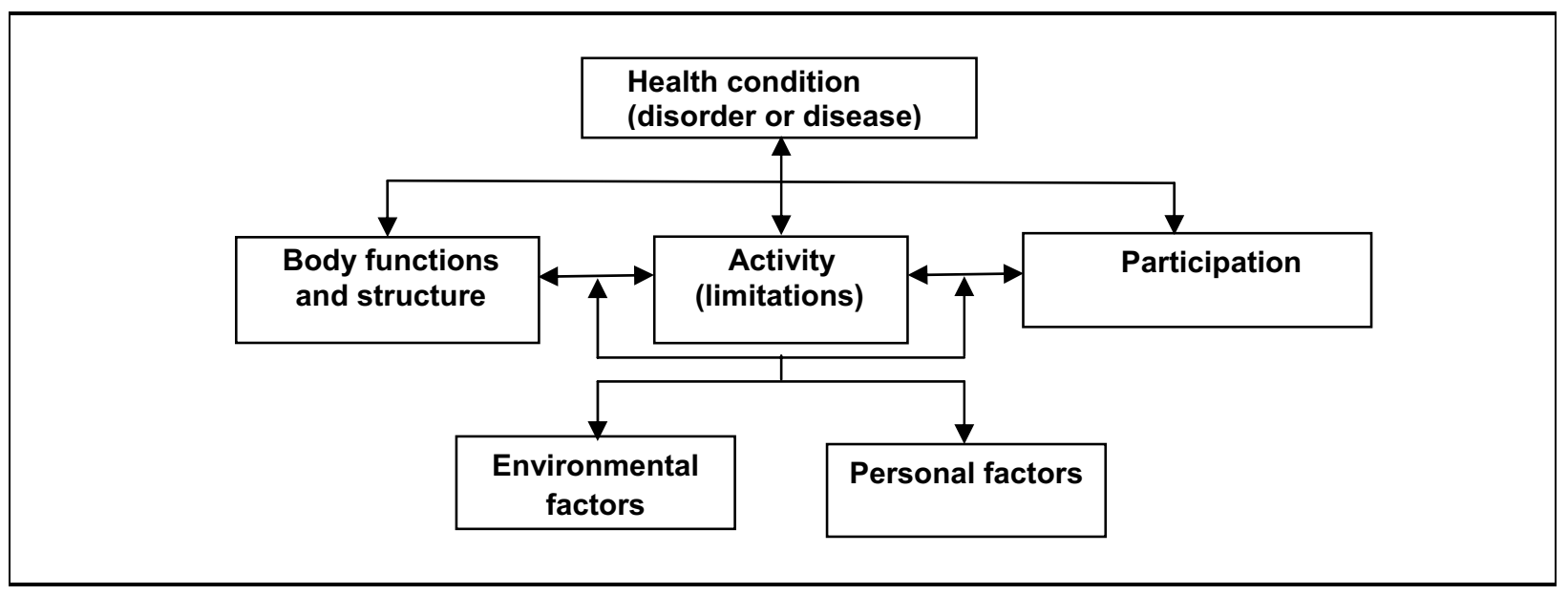

Fig. 1 From: ICF “International Classification of Functioning, Disability and Health”, World Health Organization”

\section{Discussion and conclusion}

An easy-to-use urban environment is not always something that is taken for granted.

The Administration of the City of Venice has recently changed its policy. In the past the administration had identified some strategic routes, making numerous pedestrian bridges accessible by installing stair-lifts which, as is known, can be used for long-term periods and in non-autonomous conditions. Recently it has also opted for widespread accessibility to public water transport: an inclusive Design for All solution.

Also in Venice, the bridge of the Constitution designed by the architect Calatrava for connecting Piazzale Roma, the bus and car terminal, to the train station and pedestrian city, has been the butt of endless controversies because of its cost, and the presence of steps with glass treads which are slippery in the rain and hazardous for everyone, especially visitors carrying luggage (Figures 2-3). Even more recently, a cable car has been installed for exclusive 
use by people with reduced mobility together with accompanying persons: definitely not a DFA solution.

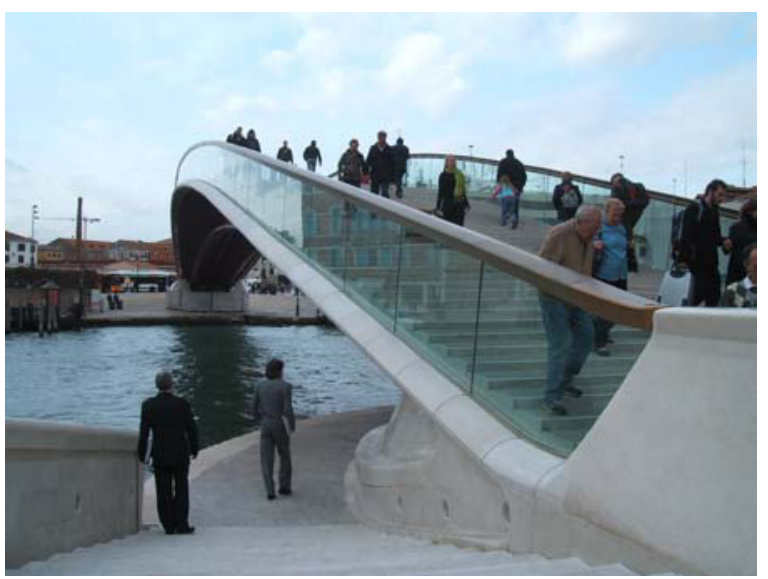

Fig. 2. Ponte della Costituzione by Santiago Calatrava, Venice

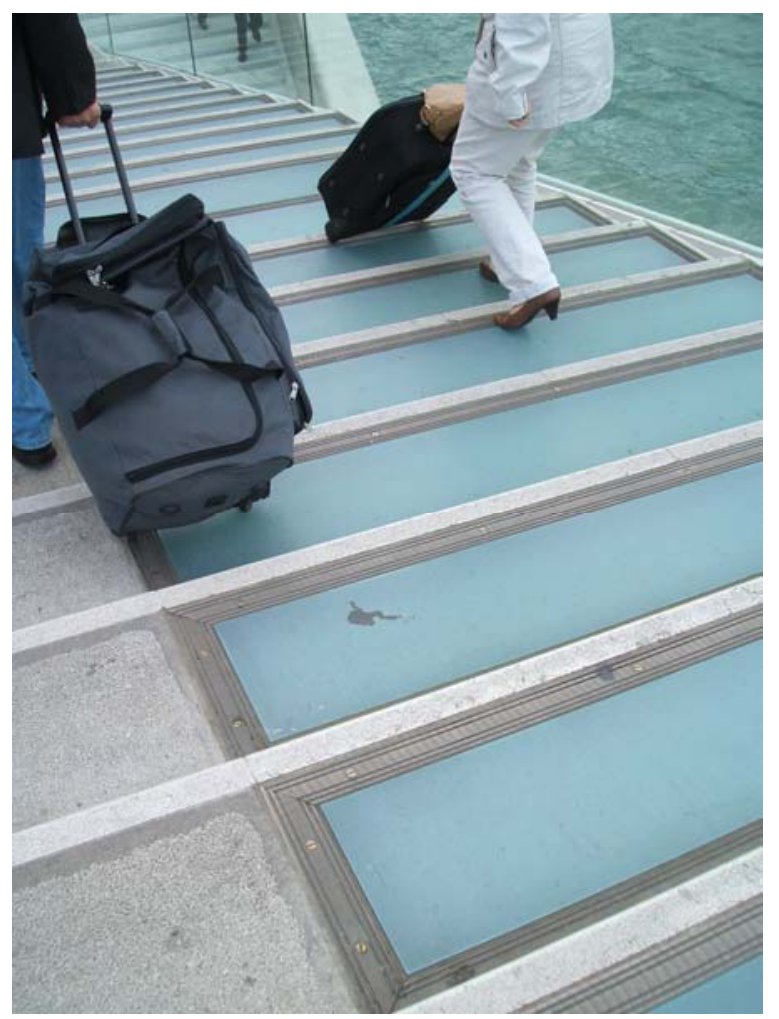

Fig. 3. Ponte della Costituzione: detail
Fatigue, adaptation to the environment with a minimum of physical effort compared to the variability of human thresholds, the need to rest also within the urban context, stimulate thought on how to address the issue of street decor and furniture and how to search for new, enhanced solutions. Several years ago, a pathway was built in Rome connecting the Pantheon to the Trevi Fountain (Fig. 4) with so-called sciatic-nerve resting points, useful for those who have difficulty sitting down and getting up.

This path has also been fitted with tactile markings on the ground and Braille and 2D maps (Fig. 5).

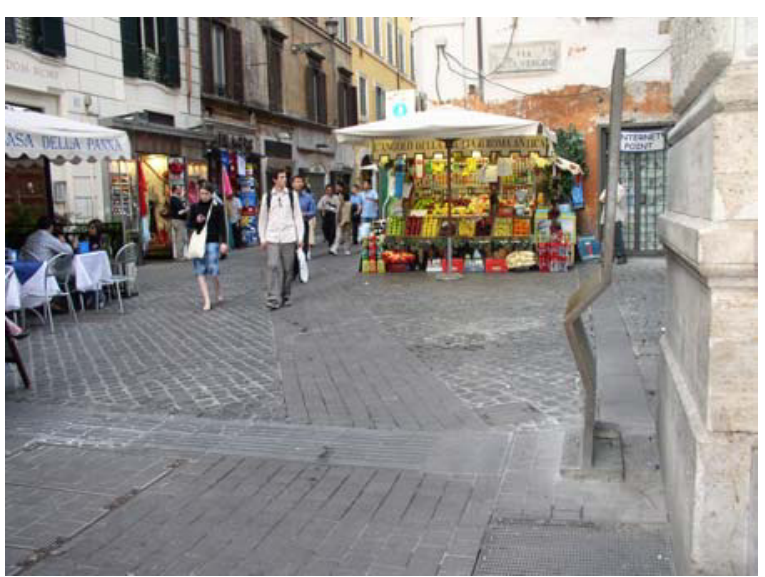

Fig. 4. Tactile path, Rome 


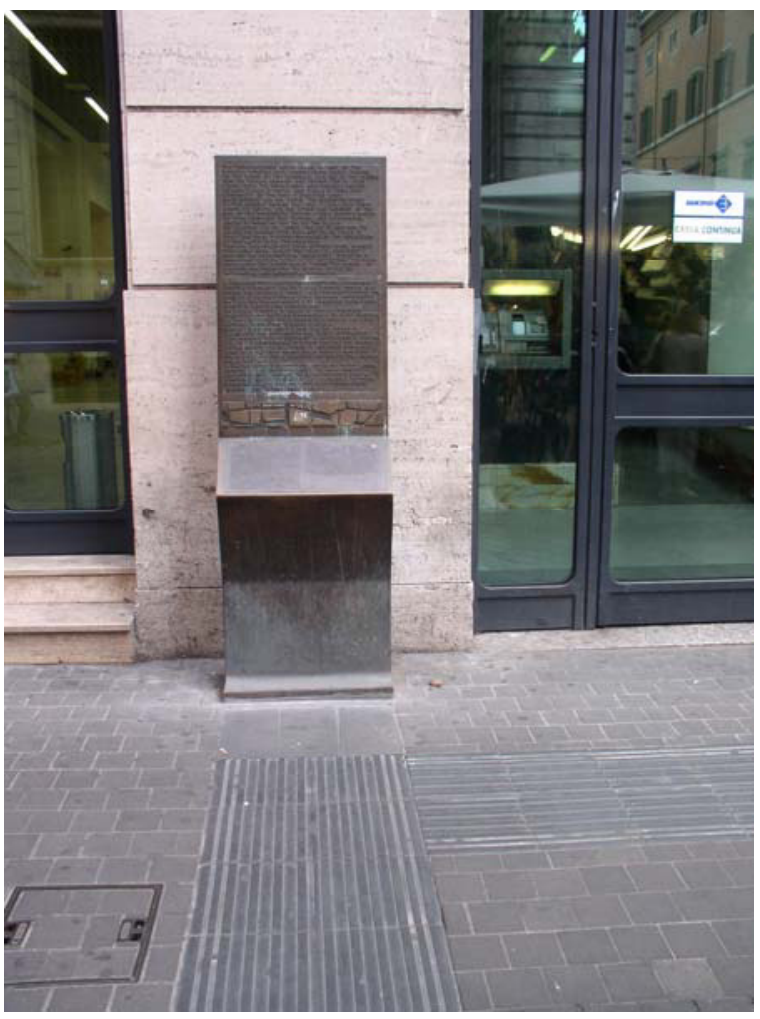

Fig. 5. Tactile map, Rome

Numerous pathways have been built in Rome with tactile signals on the ground for facilitating mobility and orientation for everyone (Fig. 6), especially at road crossings and in railway stations. The Auditorium in Rome, designed by Renzo Piano, has been equipped with tactile signs on the ground, tactile maps, and iconic and tactile signals to meet the needs of the blind and visually impaired.

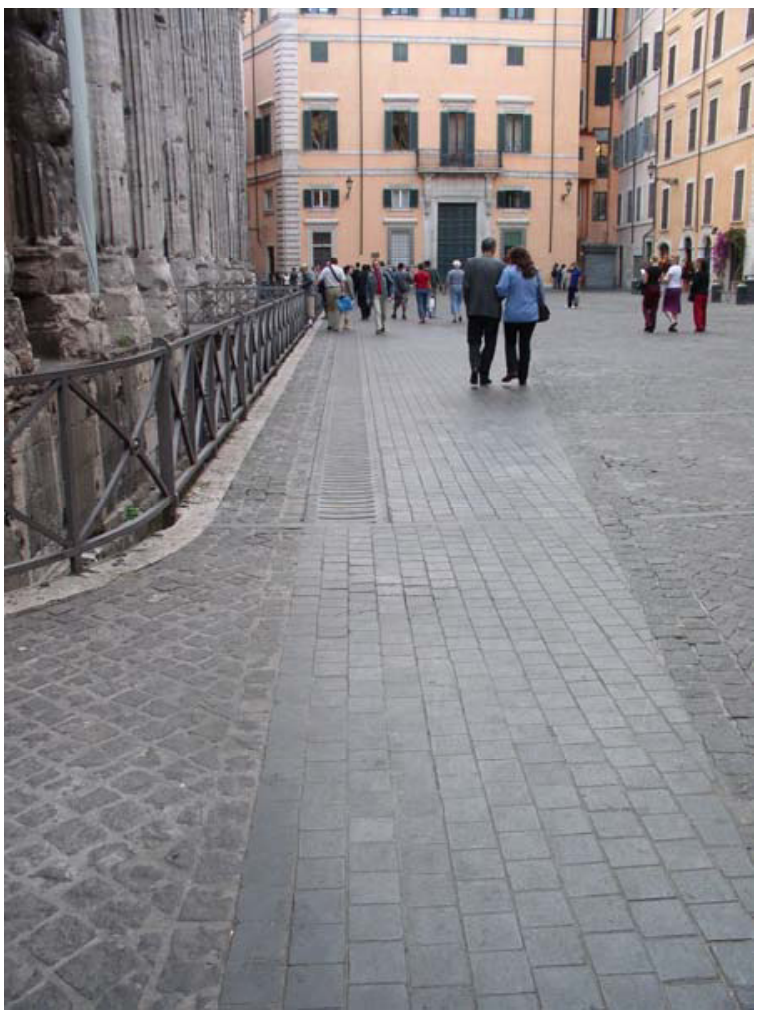

Fig. 6. Route for all, Rome

Instead, the restructuring of the Garibaldi intermodal station in Milan was not seen as an opportunity for providing a sign system for everyone. The coloured effects on the floor, although attractive, have a purely aesthetic value, not at all useful for orientating or helping people to reach the metro, railways, or railway links.

An ergonomic, DFA approach was instead successfully used by the City of Milan to evaluate the emergency City Point, which will be discussed at this conference in another paper.

The right to enjoy a safe and easy pedestrian network should involve all pedestrians, irrespective of whether their differentiated needs depend on age, physical and perceptual skills, or a personal cultural and psychological approach. It is therefore important to create pathways and environments that offer accessibility and mobility to the greatest possible number of people. The autonomous mobility of weaker users, namely, the possibility of moving about in the environment without an accompanying person and without requiring excessive physical and mental effort to adapt in relation to human thresholds, must take into consideration human abilities that may 
differ greatly one from the other: the potential to walk should become the common denominator of all different users ${ }^{4}$. Autonomous mobility also means the possibility of orientating oneself, that is, the subjective capacity of knowing where you are in the environment in absolute terms, and compared to your departure point and destination: this is a complex perceptual-cognitive process of gathering and processing sensory information from the environment and from your own body. The theme of orientation, recognition of places and perceptibility of space, is a particularly critical issue when considering the needs of people with cognitive or visual disabilities, and the elderly.

In order to understand how difficult it is for a visually impaired person to move around independently, it is sufficient to bear in mind that when walking, human beings use the visual channel to collect just on $90 \%$ of their environmental information. This fact should also influence urban planning choices: for example, the roundabouts that are replacing normal intersections everywhere allow a free traffic flow that is incompatible with the needs of the blind and visually impaired. Recent research sponsored by the Access Board, the National Eye Institute, and the American Council of the Blind has demonstrated that some roundabouts may represent a serious risk for blind people.

Whenever homogeneous and hardly perceptible materials are used, especially in the presence of even slight height differences, problems arise in relation to the safety of all pedestrians, depending on the environmental conditions.

However, there are currently no specific legal regulations on the perceptibility of obstacles or their associated hazards.

Starting from the ergonomic approach, human variability should be more conscientiously taken into account by planners and designers as a key point in the relationship between man and the built-up environment. The design solutions do not necessarily have to provide exhaustive answers to all needs, but they must be articulated in terms of compatibility with differentiated needs.

\footnotetext{
4 "Town and infrastructure planning for safety and urban quality of pedestrian", within COST Action C6 took as reference measure the capability to cover a distance without fatigue.
}

\section{References}

[1] L. Bandini Buti, Ergonomia olistica, Franco Angeli, Milano 2008

[2] L. Burzagli, P.L. Emiliani, I. Steffan, "Design for All in Italy: the results of an interdisciplinary workshop", Design for All Institute of India Newsletter, 2007;

[3] L. Fantini, I. Steffan, (edited by), Quaderni tecnici sulla fruibilità ambientale. Guida alla progettazione senza barriere architettoniche secondo l'applicazione delle prescrizioni di legge. Comune di Milano, 2002

[4] P. Felli, A. Lauria, A. Bacchetti, Comunicatività ambientale e pavimentazioni. La segnaletica sul piano del calpestio, ETS, 2004

[5] W.S. Green, P.W. Jordan, (edited by), Pleasure with products, beyond the usability, Taylor \& Francis, Londra 2002

[6] A. Freudenthal, Transgenerational guidelines. In: W.S. Green, P.K. Jordan, (edited by), Human factors in product design. Londra: Taylor \& Francis, Londra 1999

[7] M. Gussoni, O. Parlangeli, F. Tosi, Ergonomia e progetto della qualità sensoriale, Franco Angeli, Milano 2008

[8] M. Leonardi, L'ICF e i nuovi concetti di funzionamento e disabilità, Atti del Convegno "La classificazione ICF in Italia 2001-2009 Esperienze e progetti a confronto" Trento, 2009

[9] M. Leonardi, Disabilità oggi: la classificazione internazionale della funzione e della disabilità dell'Organizzazione Mondiale della Sanità. ICIDH-2. In: Valobra R. Medicina Fisica e Riabilitazione. Vol. 1; Capitolo 2: 11-19, 2000

[10] I. McClelland, Usability evaluation in industry, Taylor \& Francis, Londra 1996

[11] I. Steffan, " Laws and Plans for Accessibility of Public Buildings in Italy", in Proceedings of the POLIS /BAS International Conference "Universal Design of Building: Tools and Policy", Bruges, 16 November 2006

[12] F. Tosi, Ergonomia e progetto, Franco Angeli, Milano 2006

[13] World Health Organization (2001): World Health Report 2001: Mental Health: New understanding New Hope. World Health Organization; Geneva

[14] World Health Organization (2001) International Classification of Functioning Disability and Health. World Health Organization. Geneva. Switzerland.

[15] World Health Organization (1992-94) International Statistical Classification of Diseases and related health 
problems-Tenth Revision. ICD-Vols. 1-3. WHO. Geneva. Switzerland.

[16] World Health Organization (2001) WHO publishes new guidelines to measure health. WHO Press release WHO/48.15 November 2001. WHO Geneva. Switzerland

[17] World Health Organization (2001a). Towards a common language for functioning and disability: ICIDH-2. The international classification of functioning, disability and health. WHO. Geneva. Switzerland WHO/EIP/GPE/CASD/01.3 